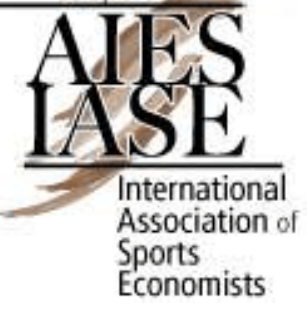

\title{
An Evaluation of the Economic Impact of National Football League Mega-events
}

\author{
Robert Baade $^{\dagger}$ and Victor A. Matheson ${ }^{\dagger \dagger}$
}

October 2011

\begin{abstract}
This paper evaluates the magnitude and the economic impact of NFL mega-events including the Pro Bowl and Super Bowl. The paper also reviews the theory behind the usual findings that the observed economic benefits of mega-events are almost always a fraction of the benefits claimed a priori.
\end{abstract}

JEL Classification Codes: L83, R53

Keywords: football, impact analysis, Super Bowl, sports, mega-event, Pro Bowl

${ }^{\dagger}$ Department of Economics and Business, Lake Forest College, Lake Forest, IL 60045, 847-735-5196 (phone), baade@lfc.edu

${ }^{\dagger}$ Department of Economics, Box 157A, College of the Holy Cross, Worcester, MA 01610-2395, 508-793-2649 (phone), 508-793-3708 (fax), vmatheso@ holycross.edu 


\section{Introduction}

Cities, regions, states, and countries compete vigorously with one another for the right to host mega-events. Political conventions, religious conferences, and sports events such as the Summer and Winter Olympic Games, the World Cup, Commonwealth Games, and the Pan American Games qualify as mega-events. Competition for these events has intensified given the common perception that they have the capacity to transform the economic landscape in the cities and countries that host them.

Heated competition exists within the United States to host mega-sports events for the same reason identified for events with global appeal. Professional sports leagues in the United States have parlayed the promise of hosting their hallmark events into financial gain, and arguably the National Football League (NFL) has done that more efficaciously than any other of the four major sports leagues operating in North America. The NFL's success is attributable to its position as the most popular of the team sports in the United States. Given its stature the NFL's championship and all-star games are particularly appealing to cities who bid for them. The prospect of substantial economic benefit from NFL hallmark events has given voice to a cadre of civic cheerleaders who extol the virtues of serving as hosts. Hosting, however, comes at a price, and the booster claims have evolved into justifications for the use of public funds or other civic subventions to host the NFL's showpieces. The purpose this chapter is to evaluate the economic impact of hosting the NFL's Super Bowl, the all-star game, and the draft of new players.

The focus in this chapter is primarily on the Super Bowl, the NFL's quintessential mega-event. The rationale for emphasizing the Super Bowl is that given its stature, the 
other NFL significant proceedings will induce an economic impact less than the Super Bowl. If the Super Bowl does not generate a meaningful increase in economic activity for the host community, it is less likely that events that are smaller in scope will stimulate the host city's economy.

This chapter is organized as follows. Section one provides a context for the Super Bowl and NFL all star games within the panoply of mega-sports events. The second part of this chapter discusses the uniqueness of the NFL as it relates to the costs involved in hosting an NFL hallmark event. The benefits that accrue to the host cities of their hallmark event are analyzed in the third section. The methodology prevalent in beforethe-event or ex ante studies used by the boosters to justify public subsidies for megaevents is discussed in the fourth section. Section five critiques the methodological approach used by apologists for public subsidies. An alternative methodology for assessing the impact of NFL hallmark events is identified and discussed in the sixth section. The estimated economic impacts of NFL mega-events are detailed and discussed in the chapter's seventh section. Conclusions and policy implications are presented in the final section of the report.

\section{How Big is the Super Bowl}

It is important to provide a context for the NFL's showcase events which include the Super Bowl, the Pro Bowl, and player draft. Cities, after all, could bid for a number of mega-sports events. It is useful to have a sense of where the NFL's events fit into all those put out for bid. The bigger the proceeding, the more likely it will stimulate the host city's economy. This section of the paper focuses on the size of the Super Bowl to provide a basis for understanding the potential impact of the NFL's mega-events. 
No definition exists for hallmark sports events, but certain characteristics are common to them. As the term suggests a mega-event is defined by scale, which if sufficiently large increases the likelihood that it induces a measurable economic impact through increasing tourism and media coverage. Conventional wisdom would identify the World Cup as a mega-sports event, and a context for the potential economic impact of the Super Bowl could be provided by comparing the audience and the revenues for the American football championship to that of the soccer world championship. The information recorded in Table 1.1 provides some measures, admittedly imperfect, for comparing the two events.

Table 1.1

Select Statistics Comparing the Super Bowl to the World Cup

\begin{tabular}{|c|c|c|}
\hline Statistic/Event & Super Bowl & World Cup \\
\hline Viewership & 106.5 million $^{\text {a }}(2010)$ & $\begin{array}{c}715.1 \text { million }(2006 \text { final) } \\
\text { and an estimated 26.29 } \\
\text { billion for all 64 games } \\
(2006)\end{array}$ \\
\hline Number of Games & 1 & 64 \\
\hline Total Time Played & 60 minutes & 96 hours \\
\hline Ad Revenue & $\$ 213$ million $(2009)$ & $\begin{array}{c}\$ 1 \text { billion (estimated for } \\
2006)\end{array}$ \\
\hline Ticket Price & $\$ 800-\$ 1,000(2010)$ & $\$ 400-\$ 900(2010$ final) \\
\hline $\begin{array}{c}\text { Ad Revenue per minute of } \\
\text { playing time }\end{array}$ & $\$ 355,000$ & $\$ 176,000$ \\
\hline
\end{tabular}

Source: http://matadornetwork.com/sports/the-world-cup-is-246x-bigger-than-the-superbowl

${ }^{\mathrm{a}}$ This represents the largest audience ever to view a television program in the United States displacing the final episode of $M A S H$.

The statistics recorded in Table 1.1 indicate that by the measures indicated, the Super Bowl and the World Cup qualify as mega-sports events on a global scale, even though the Super Bowl viewing audience is primarily U.S. based. 
The potential importance of the Super Bowl can be brought into somewhat sharper focus by comparing it to two other distinctly American mega-events: the NCAA Final Four and the World Series. Comparative statistics for the three mega-events are recorded in Table 1.2.

Table 1.2

Statistics Comparing the Super Bowl to the NCAA Final Four and the World Series

\begin{tabular}{|c|c|c|c|}
\hline $\begin{array}{c}\text { Year/Event and Ad } \\
\text { Revenue } \\
\text { (\$Millions) }\end{array}$ & Super Bowl & $\begin{array}{c}\text { World Series } \\
\text { (Number of } \\
\text { Games) }\end{array}$ & $\begin{array}{c}\text { NCAA Men's } \\
\text { Basketball Final } \\
\text { Four (Number of } \\
\text { Games) }\end{array}$ \\
\hline 2002 & 134.2 & $141.2(7)$ & $101.3(3)$ \\
\hline 2003 & 130.1 & $124.3(6)$ & $117.6(3)$ \\
\hline 2004 & 149.6 & $113.4(4)$ & $126.4(3)$ \\
\hline 2005 & 158.4 & $146.9(4)$ & $142.2(3)$ \\
\hline 2006 & 162.5 & $160.5(5)$ & $154.7(3)$ \\
\hline 2007 & 151.5 & $156.6(4)$ & $168.4(3)$ \\
\hline
\end{tabular}

Source: http://www.datasofa.com/app\#/data_sets/1142

The information clearly indicates that per game the Super Bowl generates more ad revenue than either of the other mega-sports events that are uniquely American. Having established the mega-event status of the Super Bowl, the costs incurred in hosting the event are identified and distinguished from the costs involved in hosting other megaevents.

\section{Costs Incurred in Hosting an NFL Mega-event}

Suitor cities understand that competing to host a mega-sports event will require significant costs that almost without exception will necessitate public funding. ${ }^{1} \mathrm{~A}$

\footnotetext{
${ }^{1}$ An exception to this occurred with the 1984 Los Angeles Summer Olympic Games. The exception is attributable to the fact that the City of Los Angeles was the only city bidding for the Games in 1984 . The
} 
substantial portion of those costs involve the construction of infrastructure that will provide playing venues as well as transportation, communication, and accommodation for officials and spectators attending the event. Studies of sports mega-events do indicate that sustainable economic impact from a hallmark event is likely the result of infrastructure embellishment relating to event accommodation in the transportation, communication, and hospitality sectors of the economy rather than venue construction. Given the fact that the Super Bowl is a one-day event, a rationale for public subsidies differ in at least two ways from that of the Olympics and the World Cup events, which require infrastructure to meet the needs of fans for a fortnight at least. First, the NFL can argue with little conviction that the duration of the event requires the development of ancillary infrastructure indirectly needed to accommodate the event, which will serve as a stimulus for sustainable economic activity. Second, the lack of a rationale for ancillary infrastructure development focuses attention on the stadium alone as the catalyst for an increase in economic activity attributable to the event. The NFL, therefore, cannot encourage the development of ancillary infrastructure for the event in the same way that the International Olympic Committee (IOC) or the Federation Internationale de Football Association (FIFA) can. The NFL has had to devise a strategy to encourage potential host cities to bid for the Super Bowl. ${ }^{2}$

The NFL has linked the designation of a host city for the Super Bowl to the willingness of a team to construct a new stadium, and, at least tacitly given the enormous cost involved, to the willingness of the host city to support that construction with

\footnotetext{
International Olympic Committee (IOC) was in no position, therefore, to compel the construction of infrastructure as is typical with multiple suitor cities.

${ }^{2}$ It should be noted that, all else equal, the more participants there are in an auction, the more likely that the winning bid will exceed the benefit from the auctioned item. The benefit from hosting the Super Bowl is the economic impact that it ostensibly yields.
} 
taxpayer dollars. The NFL has helped even the most parsimonious cities justify those public subsidies through sponsoring studies that indicate that the Super Bowl induces an increase in economic activity in the host city that numbers in the hundreds of millions of dollars. The situation in Atlanta presently provides a good example of the NFL's strategy.

The NFL Atlanta Falcons currently play in the Georgia Dome, a 71,000 seat stadium that is eighteen years old. The bonds on the Georgia Dome will not be paid until 2018 or 2019, but Roger Goodell, the Commissioner of the NFL, has indicated that the construction of a new open-air stadium would bring the Super Bowl back to Atlanta. Goodell observed:

The bar has been raised because you're getting facilities around the country in great communities. These games (Super Bowl) are a tremendous value to the communities and there's a lot of competition for it. So I think a new stadium with this great community (Atlanta) would be beneficial to bringing another Super Bowl to this community. ${ }^{3}$

Commissioner Goodell's posture echoes that of his predecessor, Paul Tagliabue, who devised the 'stadium for Super Bowl' gambit. The 2008 Super Bowl, for example, was played in the University of Phoenix stadium in Glendale Arizona two years after the stadium opened on August 1, 2006. The Arizona Sports and Tourism Authority contributed $\$ 300.4$ million to the project after a long bitter battle for public funding.

The Super Bowl inducement to NFL cities to build or renovate stadiums now includes cold weather cities, and that expands the pool of metropolises bidding for the Super Bowl. The fact that the 2014 Super Bowl will be held in the new $\$ 1.6$ billion Giants-Jets Stadium in the Meadowlands will likely lead to very active bidding for the

\footnotetext{
${ }^{3}$ NFL.com news, "Goodell: New stadium would bring Super Bowl back to Atlanta," http://www.nfl.com/news/story/09000d5d81c0b6bc/article/goodell-new-stadium-would-bring-super-bowlback-to-atlanta.
} 
Super Bowl beginning in 2018 as the Super Bowls in 2015, 2016, and 2017 are scheduled to be played in warm weather or indoor stadiums. Commissioner Goodell has indicated that depending on the New York experience in 2014, future Super Bowls could be played in cold-weather cities. A larger pool of potential cities, all else equal, will likely lead to increased financial pressure on cities for public funding of stadiums, the price cities pay for hosting the Super Bowl event.

The cost of hosting a Super Bowl exceeds the direct cost of a new stadium for the host city since indirect costs are also incurred. Referring back to Atlanta, if Atlanta had two stadiums that could host football, then the competition between them would reduce rents for other events that the stadiums could accommodate. The additional debt service imposed by another stadium could have implications for the bond rating for Atlanta in particular and for other cities pursuing the aggressive stadium strategy articulated by Commissioner Goodell.

On a national stage, new stadiums with new revenue generating amenities exacerbate the pressure teams can exert on cities to build new, state of the art facilities. Some teams have contracts with provisions for lease escape should their stadium not measure up to the current standard. Consider the contract for the St. Louis Rams as noted by Peter Callaghan. In referring to the example set by the $\$ 1.2$ billion new Dallas Cowboys stadium, Callaghan observed:

Every time an announcer referred to the new stadium as "state of the art" (as though any new building isn't), Rams fans might have been wondering how long their team would be around. 
That's because the Rams, playing in the not-so-long-ago-state-of-the-art Edward Jones Dome are threatening to move even though the stadium is just 14 years old. Under the lease, if the stadium isn't among the eight most-state-of-the-art in the National Football League, the team can demand that it be improved. By next season, 23 stadiums will have been built or renovated since St. Louis built the dome. ${ }^{4}$

The direct costs to the host city entail more than the stadium. Services and security costs are significant and controversial especially now as municipalities struggle to balance budgets. The City of Arlington, where the new Cowboys stadium is located, has allocated \$2 million for Super Bowl expenses to accommodate the 2011 event. Communities nearby will also incur costs in conjunction with Super Bowl XLV. Dallas and Fort Worth have committed $\$ 3$ and $\$ 4.5$ million to cover expenses anticipated in conjunction with the February 6, 2011 Super Bowl event in Arlington, Texas. ${ }^{5}$

The NFL Pro Bowl, the other NFL mega-event involving on-field competition, costs a significant amount of money for the host city, and that cost is likely to rise in the future given that the NFL awarded the 2010 event to Florida rather than Hawaii. The Pro Bowl had been played in Hawaii for 30 years prior to 2010, and it will return to Hawaii in 2011. The NFL has made no commitment beyond 2011, and that lack of commitment likely implies that the event is out for bid. The NFL Pro Bowl is the largest and most expensive event hosted by the Hawaii Tourism Authority (HTA). The HTA paid the NFL $\$ 5.3$ million for the rights to host the event in 2004, and that sum paid to the NFL

\footnotetext{
${ }^{4}$ Peter Callaghan, "New stadium could spark Round Two of tax subsidy begging," The News Tribune, September 29, 2009, http://www.thenewstribune.com/2009/09/29/897268/new-stadium-could-sparkround.html.

${ }^{5}$ Jason Whitley, "Cities spending millions to stage Super Bowl," WFAA.com, http://www.wfaa.com/news/local/Cities-spending-millionsto-stage-Super-Bowl-XLV-10.
} 
constituted more than 66 percent of the HTA budget devoted to sponsoring events (Baumann et al. 2009).

The substantial costs incurred by cities who do host the Super Bowl and the Pro Bowl are justified by the NFL through league-commissioned studies measuring the impact of the events on the host city's economy. The next section of this chapter identifies and discusses the magnitude of the economic impact host cities can expect according to the league-sponsored studies.

\section{The NFL Rationale for Hosting the League's Hallmark Events: The League's Measure of Economic Impact}

Joint studies conducted by the National Football League (NFL) and various economic consulting firms have estimated an economic impact from the Super Bowl XXXIII of between $\$ 300$ and $\$ 500$ million on local economies. If those numbers are accurate, "Super" is indeed an apt description of the event. Only a handful of other sporting events such as the Summer and Winter Olympic Games or soccer's World Cup and Champions League final can seriously be thought to generate an impact of such magnitude. Booster studies in general have estimated an economic impact of $\$ 300$ to \$500 million in current dollars from the Super Bowl as the information in Table 1.3 below indicates.

Table 1.3

Economic Impact Estimates Provided by Boosters for Selected Super Bowls between 1995 and 2003

\begin{tabular}{|c|c|c|c|}
\hline Year & Author & City & $\begin{array}{l}\text { Estimate in millions } \\
\text { of \$ and (in millions }\end{array}$ \\
\hline
\end{tabular}




\begin{tabular}{|c|c|c|c|}
\hline 1995 & $\begin{array}{c}\text { NFL and Kathleen } \\
\text { Davis, Sports } \\
\text { Management Research } \\
\text { Institute }\end{array}$ & Miami & $\$ 365(\$ 412.4)$ \\
\hline 1998 & PriceWaterhouseCoopers & San Diego & $\$ 295(\$ 311.7)$ \\
\hline 1999 & $\begin{array}{c}\text { NFL and Kathleen } \\
\text { Davis, Sports } \\
\text { Management Research } \\
\text { Institute }\end{array}$ & Miami & $\$ 393(\$ 406.2)$ \\
\hline 2000 & Jason Ader, Bear Stearns & Atlanta & $\$ 410(\$ 410)$ \\
\hline 2000 & Jeffrey Humphreys & Atlanta & $\$ 292(\$ 292)$ \\
\hline 2003 & $\begin{array}{c}\text { Super Bowl Host } \\
\text { Committee }\end{array}$ & San Diego & $\$ 375(\$ 356.8)$ \\
\hline 2007 & PriceWaterhouseCoopers & Miami & $\$ 390(\$ 406.5)$ \\
\hline 2008 & $\begin{array}{c}\text { W.P. Carey MBA Sports } \\
\text { Business Program }\end{array}$ & Phoenix & $\$ 500.6(\$ 500.9)$ \\
\hline
\end{tabular}

Source: Baade and Matheon (2006), "Padding Required: Assessing the Economic Impact of the Super Bowl," European Sport Management Quarterly, Vol. 6, No. 4, December, p.355, and various media sources.

Tacitly, the NFL-commissioned studies envision hordes of affluent, non-resident spendthrifts descending on the host city for its mega-events. The NFL-SMRI team reported that the average income of Super Bowl attendees is more than twice that of the average visitor to South Florida during the peak tourist months of January and February ( $\$ 144,500$ compared to $\$ 40,000-\$ 80,000$ ), and they spend up to four times as much as the average visitor to South Florida ( $\$ 400.33$ per day compared to $\$ 99-\$ 199$ per day). Jim Steeg, who served as the NFL's Vice President for special events for 26 years beginning in 1977, puts the Super Bowl at the center of the mega-event universe.

The Super Bowl is the most unique of all special events. Extensive studies by host cities, independent organizations and the NFL all try to predict the economic impact the big game will have on a community. They talk to tens of thousands of attendees, 
local businessmen, corporate planners, media and local fans -- looking to see how they are affected.

These studies have provided irrefutable evidence that a Super Bowl is the most dramatic event in the U.S. Super Bowl patrons are significantly more affluent, spend more and have more spent on them, and influence future business in the community more than attendees of any other event or convention held in the U.S. (Steeg 1999).

Steeg based his Super Bowl claims on several factors. Most prominent among them from his perspective were: the substantial spending by the NFL and NFL Properties; ${ }^{6}$ the number of visitors from outside the community who attended the game and related events; and the ideal fit of the Super Bowl into the convention calendar. The Super Bowl, Steeg opined, has the capacity for transforming the historically slack month of January into a convention windfall for the host city.

It is noteworthy that the economic impact generated by the Super Bowl often approximates public subsidies for stadium construction in the NFL. It is conceivable that the public subsidy for a new stadium can be recouped through hosting the Super Bowl. The NFL has used this argument to convince host NFL cities that an investment in a stadium is a sound business decision.

Hosting the Pro Bowl follows a similar cost-benefit-analysis logic. Baumann, Matheson, and Muroi (2009) noted:

...the HTA estimated that the 2007 Pro Bowl attracted 27,625 visitors to Hawaii resulting in US\$28.03 million in visitor spending US\$2.72 million in tax collection. Second, the HTA suggests that sporting events serve to publicize Hawaii to prospective tourists...Third, these events may improve the quality of life of the Island's residents by

\footnotetext{
${ }^{6}$ Steeg claimed that the NFL and NFL Properties spend a combined $\$ 43$ million on Super Bowl XXXIV, for example.
} 
allowing them opportunities to watch or participate in the major sporting events. $^{\text {? }}$

If the economic impact studies are correct, then hosting these events are justified on economic grounds. The next section of the paper evaluates the methodology used by boosters for hosting the NFL mega-events, and discusses the implications for the economic impact studies used to rationalize the use of public money to host these events.

\section{Evaluating the Methodology of League Ex Ante Economic Impact Studies}

The NFL has been successful in encouraging cities to financially support the construction of new infrastructure for its teams. The NFL represents the teams to include promoting their financial interests. The League's strategic success in convincing host cities to build team infrastructure requires further scrutiny. It may be that the League's interests do not mesh with those of society, and League authored estimates may not accurately represent the true impact of the Super Bowl for host cities. A motivation for embellishing the impact does exist.

Many scholars not directly connected to the NFL disagree with League inspired estimates on the economic impact of the Super Bowl. The significant differences among the economic impact estimates from the Super Bowl call into question estimation techniques of those who stand to gain from hosting the event. Defined in 2000 dollars, the $\$ 120$ million difference between the high (Miami, Florida) and low estimate (Atlanta, Georgia) of the economic impact from the Super Bowl as identified in Table 1.3 is not trivial. Jeffrey Humphreys, the author of the low number, also assessed the impact of Super Bowl XXVIII on the city of Atlanta and the state of Georgia. Humphreys

\footnotetext{
${ }^{7}$ Robert W. Baumann, Victor A. Matheson, and Chihiro Muroi (2009), "Bowling in Hawaii: Examining the Effectiveness of Sports-Based Tourism Strategies," Journal of Sports Economics, 10, 109.
} 
estimated that the event created 2,736 jobs and had an impact of $\$ 166$ million on the Georgia economy (Humphreys, 1994). Of the $\$ 166$ million, Humphreys estimated a direct and indirect economic impact of $\$ 76$ and $\$ 90$ million, respectively. The direct impact was derived from estimating the number of "visitor days" $(306,680)$ and multiplying that statistic by the average estimated per diem expenditures per visitor (\$252). The indirect or induced economic impact was estimated using the Regional Input-Output System (RIMS II) model developed by the Bureau of Economic Analysis. Humphreys estimate for 1994 for the Super Bowl's economic impact on Atlanta was in current dollars \$126 million less than the estimated impact for the Super Bowl on the same city six years later. A portion of the $\$ 126$ million dollar difference can be explained by price changes over the six-year period, but the differences suggest other possible explanations, some of which are apparent in accounting for the roughly \$227 million difference in current dollars between the estimates of economic impact for Super Bowls XXXIII and XXVIII. Most of the difference between those two real estimates is attributable to the number of visitors and the daily spending attributable to each of them.

The differences in economic impact from the Super Bowl go beyond visitor numbers and daily spending. Phil Porter provided a far less sanguine appraisal of the Super Bowl's economic impact (Porter, 1999). Porter used regression analysis to determine that the impact of the event was statistically insignificant, that is not measurably different from zero. After reviewing short-term data on sales receipts for several Super Bowls, Porter concluded:

Investigator bias, data measurement error, changing production relationships, diminishing returns to both scale and variable inputs, and capacity constraints anywhere along the chain of sales relations lead to lower multipliers. Crowding out and price increases by input suppliers in 
response to higher levels of demand and the tendency of suppliers to lower prices to stimulate sales when demand is weak lead to overestimates of net new sales due to the event. These characteristics alone would suggest that the estimated impact of the mega-sporting event will be lower than the impact analysis predicts. ${ }^{8}$

Similarly an examination of twenty-five Super Bowls from 1973 to 1997 by Baade and Matheson found the game correlated with an increase in metropolitan area employment of 537 jobs for the host. Based on simple assumptions regarding the value of a job to a community, they estimate an average economic impact of roughly $\$ 30$ million less than one-tenth the figures touted by the NFL (Baade and Matheson 1999). An examination of all post-season play in American professional sports found that hosting the Super Bowl had no statistically significant effect on per capita income in the host city (Coates and Humphrey 2002).

From 1995 through 2003, roughly the same period for the sample of economic impact estimates in Table 1.3 approximately $\$ 6.4$ billion, an average of $\$ 304$ million, was spent to build or substantially refurbish twenty-one NFL stadiums. The public contribution was $\$ 4.4$ billion, an average of $\$ 209$ million, or roughly 69 percent of the construction costs of these facilities (Peter 2002). Another $\$ 4.7$ billion was spent on another six NFL stadiums between 2006 and 2011 over \$2 billion of which was public money. The NFL has offered the Super Bowl as an inducement to convince otherwise reluctant cities that the construction of a new stadium makes economic sense. Scholars do not agree on the economic impact of the Super Bowl, and in the next section of this chapter, reasons for the disagreement are identified and analyzed.

\footnotetext{
${ }^{8}$ Philip Porter (1999), "Mega-sports events as municipal investments: a critique of impact analysis," in J.L. Fizel, E. Gustafson, and L. Hadley (eds.), Sports Economics: Current Research, New York: Praeger, 61-74.
} 


\section{Theoretically Accounting for the Differences in Economic Impact Estimates}

If there is an exaggeration of the benefits induced by a sports mega-event, it occurs for several fundamental reasons. First, the increase in direct spending attributable to the games may be a "gross" as opposed to a "net" measure. Some subsidy advocates estimate direct spending by simply summing all receipts associated with the event. The fact that the gross-spending approach fails to account for decreased spending directly attributable to the event represents a major theoretical and practical shortcoming. Surveys on expenditures by those attending the event, complete with a question on place of residence, would appear to be a straightforward way of estimating direct expenditures in a manner that is statistically acceptable. Such surveys may well provide acceptable spending estimates for those patronizing the event, but they do not reveal changes in spending by residents not attending it. It is conceivable that some local residents or potential visitors may dramatically change their spending given their desire to avoid the congestion at least in the venue's environs. A basic shortcoming of typical economic impact studies, in general, pertains not to information on spending by those included in a direct expenditure survey, but rather to the lack of information on the spending behavior for those who are not.

Baade (1996) cited the failure to account for the difference between gross and net spending as a chief reason why sports events or teams do not contribute as much to metropolitan economies as boosters claim. However, in the case of the Super Bowl a large proportion of all attendees come from outside the local area, and their spending qualifies as net new spending. If the host city's residents who do not attend do not reduce their expenditures within the city, one might contend that direct expenditure by non- 
residents who attend events approximates net impact. Unfortunately, this will not be true if some nonresidents, who might have visited the city, decide not to do so because of congestion and high prices during the Super Bowl or the Pro Bowl. In addition, some Super Bowl fans may have already been planning on visiting a city but rearrange their schedule to accommodate the game. Even though the economic analyst may attribute this visit to the Super Bowl, in fact, this type of time switching does not lead to a net increase in economic activity in the city but simply alters the time period during which the activity takes place.

Recent evidence assessing the economic impact of other mega-events indicates the importance of substitution effects. The evidence from the Summer Olympics in 2000 in Sydney, Australia, for example, indicates that certain kinds of substitution effects may be substantial even in cases where the event has a clear international character. An Arthur Andersen (2000) survey on hotel activity in Sydney and other capital cities prior to and during the Olympic Games concludes:

As expected, survey results indicate the vast majority of Sydney hotels peaking at near 100\% occupancies during the Games period from September 16-30. This represents an increase of $49 \%$ in occupancy levels relative to the first half of September. In contrast, other capital cities experienced significant demand shortfalls for the same period. For example, occupancies in Melbourne and Brisbane plummeted by $19 \%$ and $17 \%$ in the second half of September relative to the period from 1-15 September. Overall, with the exception of Sydney and Adelaide, all hotel markets in Australia experienced a decline in occupancy in September 2000 relative to September 1999 despite the Olympic Games, as reported in the Hotel Industry Benchmark Survey. Hoteliers indicate that while international demand was strong..., domestic leisure travel traditionally taking place during the September school holiday period was displaced to Sydney for the Olympics.

The Anderson report indicates the importance of substitution effects, and compels consideration of which, if any, governmental entities should be involved in subsidizing 
sports mega-events. Sydney's gains may well have come at the expense of other Australian cities, and if the federal government subsidizes the games there must be a rationale for enriching Sydney at the expense of Adelaide and other regional cities. Similarly the NFL's awarding the Super Bowl to a particular city likely has implications for other cities. A redistribution of discretionary spending from one city and region to another requires a rationale. The NFL has no compulsion for considering the distributional implications of its actions, and this may be inappropriate given that the use of local public funds for stadium projects may have interregional or even national implications.

A second reason economic impact may be exaggerated relates to what economists refer to as the "multiplier," the notion that direct spending increases induce additional rounds of spending due to increased incomes that occur as a result of additional direct spending in the "first round." If errors are made in assessing direct spending, those errors are compounded in calculating indirect spending through standard multiplier analysis. Furthermore, correct multiplier analysis includes all "leakages" from the circular flow of payments and uses multipliers that are appropriate to the event industry. Leakages may be significant depending on the state of the economy. If the host economy is at or very near full employment, for example, it may be that the labor essential to conducting the event resides in other communities where unemployment or a labor surplus exists. To the extent that this is true, then the indirect spending that constitutes the multiplier effect must be adjusted to reflect this leakage of income and subsequent spending. Siegfried and Zimbalist (2002) note that only $29 \%$ of professional athletes in their study live in the metropolitan area in which their team plays leading to very high levels of leakage from 
local expenditures on professional sports.

Labor is not the only factor of production that may repatriate income. If hotels experience higher than normal occupancy rates during the Super Bowl or Pro Bowl, then the question must be raised about the fraction of increased earnings that remain in the community if the hotel is a nationally owned chain.

Finally, most economic impact analyses use expenditure multipliers (rather than income multipliers) to assess the economic impact of an event. The use of expenditure multipliers is unjustified, however, as the important point is not how much business activity is created by an event but rather how the income of local residents is affected by it. In short, to assess the impact of mega-events, a balance of payments approach should be utilized. That is to say, to what extent does the event give rise to income inflows and outflows that would not occur in its absence? Since the input-output models used in the most sophisticated ex ante analyses are based on fixed relationships between inputs and outputs, such models do not account for the subtleties of full employment and capital ownership noted here.

Input-output models lend an air of authenticity and authority given their comprehensive description of fundamental economic relationships and their government origins, but they are based on a regional economy's "normal" productive relationships and patterns. During a mega-event, however, the economy within a region may be abnormal, and the inter-industry relationships identified in input-output tables may not hold. Intuitively, there is a potential inconsistency in attributing significant economic change to a mega-event while contending that fundamental productive relationships remain unaltered. 
As an alternative to estimating the change in expenditures and associated changes in economic activity, those who provide goods and services directly in accommodating the event could be asked how their activity has been altered by the event. In summarizing the efficacy of this technique Davidson (1999) opined:

The biggest problem with this producer approach is that these business managers must be able to estimate how much "extra" spending was caused by the sport event. This requires that each proprietor have a model of what would have happened during that time period had the sport event not taken place. This is an extreme requirement, which severely limits this technique.

While many potential criticisms of ex ante economic analysis exist, the real question, from a public policy perspective, is whether these estimates of the economic impact of the Super Bowl conform to actual or ex post estimates of the economic impact this and other NFL mega-events exert on their host cities? In the next section of this chapter, the ex post model methodology is discussed.

\section{Ex Post Model Methodology and Results}

Ex ante models may not provide credible estimates on the economic impact of a mega-event for the reasons cited above. An ex post or retrospective model may be useful in providing a filter through which the promises made by NFL mega-event boosters can be strained. A mega-event's impact is likely to be small relative to the overall economy, and the primary challenge for those doing a post-event audit involves isolating the event's impact. This is not a trivial task, and those who seek insight into the question of economic impact of the Super Bowl, Pro Bowl or NFL draft should be cognizant of the challenges and deficiencies common to both ex ante and ex post analyses. 
Several approaches are possible in constructing a model to estimate the impact an event has had on a city, and are suggested by past scholarly work. Mills and McDonald (1992) have provided an extensive summary of models that have been used to explain metropolitan economic growth. These theories seek to explain increases in economic activity through changes in key economic variables in the short-run (export base and neoclassical models) or the identification of long-term developments that enhance the capacity for growth in metropolitan economies (product cycle, cumulative causation, and disequilibrium dynamic adjustment models).

The task here is not to replicate explanations of metropolitan economic growth, but to use past work to help identify how much of an increase in economic activity in U.S. cities hosting NFL mega-events is attributable to any one of them. Estimating the economic impact of an NFL mega-event involves comparing the projected level of economic activity without an NFL mega event to the actual levels of economic activity that occurred in cities that have served as hosts. The success of this approach depends on the ability to identify variables that account for the variation in growth in economic activity in host cities in addition to the presence of the event.

Given the number and variety of variables found in regional growth models and the inconsistency of findings with regard to coefficient size and significance, criticisms of any single model could logically focus on the problems posed by omitted variables. Any critic, of course, can claim that a particular regression suffers from omitted-variable bias, but it is far more challenging to specify the model so as to remedy the problem. In explaining regional or metropolitan growth patterns, at least some of the omitted variable problem can be addressed through a careful specification of the independent variables. 
As noted above, representing relevant variables as deviations from city norms, leaves the scholar a more manageable task, namely that of identifying those factors that explain city growth after accounting for the impact of those forces that generally have affected regional or national MSA growth. It is important, for example, to model the fact that relocating a business could occur as a consequence of wages increasing in the metropolitan statistical area (MSA) under study or a slower rate of wage growth in other metropolitan statistical areas. What matters is not the absolute level of wages in any particular city, but in that city's wage relative to that of other cities.

The purpose of ex ante studies is to provide a measure of the net benefits a project or event is likely to yield. To our knowledge there is no prospective model that has the capacity for measuring the net benefits of a project relative to the next best alternative use of those funds. If one assumes that the best use of funds has always occurred prior to a mega-event, then the growth path observed for a city can be construed as optimal. If this optimal growth path, identified by the city's secular growth trend, decreases after the mega-event occurs, then the evidence does not support the hypothesis that a publicly subsidized mega-event put those public monies to the best use.

Baade and Matheson (2000), Coates and Humphreys (2002), Baade and Matheson (2006), and Maening et al. (2006), among other, have all estimated the economic impact of mega-events using many of the conventions discussed above in executing a retrospective examination. Mega-event audits by independent scholars often use regression analysis, and express the results in terms of statistical significance. Testing the hypothesis of whether the economic impact is meaningful different from zero makes it difficult to compare prospective and retrospective results, which usually identify 
economic impact estimates in currency amounts. It could be that the impact is large, but does not qualify as "meaningfully different from zero" for a large, diverse urban economy. Baade and Matheson (2006) attempted to reconcile the difference by identifying different size impacts for the Super Bowl in terms of the probability or likelihood that they would occur. The economic impact of the Super Bowl using this technique is identified in the next section of the paper along with estimates of the impact of the Pro Bowl.

\section{Ex Post Economic Impact Estimates of NFL Mega-Events}

Baade and Matheson's study in 2006 sought to predict changes in income attributable to the Super Bowl in host cities over the period 1970-2001. The cohort of cities used in their sample included seventy-three metropolitan areas that represent the largest MSAs in the United States by population over the time period 1970-2001 including every MSA that was among the largest sixty MSAs at some time during that period. While the choice of seventy-three cities is largely arbitrary, the list was expanded to include all metropolitan areas that have hosted the Super Bowl, cities with professional sports franchises (with the exception of Green Bay, WI), and MSAs with professional sports aspirations. Table 1.4 identifies the probability that different size economic impact estimates for the Super Bowl would occur based on the experience of the Super Bowls for the 31-year period noted above.

Table 1.4

Probabilities for Various Levels of Economic Impact Induced by the Super Bowl

\begin{tabular}{|c|c|}
\hline Economic Impact & $\begin{array}{c}\text { Probability of such an impact or greater } \\
\text { having occurred }\end{array}$ \\
\hline$\$ 400$ million & $0.87 \%$ \\
\hline$\$ 392.8$ million & $1.00 \%$ \\
\hline
\end{tabular}




\begin{tabular}{|c|c|}
\hline \$300 million & $5.00 \%$ \\
\hline \$252.7 million & $10.00 \%$ \\
\hline \$200 million & $19.28 \%$ \\
\hline \$100 million & $47.40 \%$ \\
\hline \$1.9 million & $50.00 \%$ \\
\hline Negative & $77.00 \%$ \\
\hline Nen & $23.00 \%$ \\
\hline
\end{tabular}

Source: (Baade and Matheson, 2006), "Padding Required: Assessing the Economic Impact of the Super Bowl," European Sport Management Quarterly, Vol. 6, No. 4, p. 372.

The figures represented in Table 1.4 were chosen based on the prevalence of booster claims in the neighborhood of $\$ 300$ to $\$ 400$ million. The information in Table 1.4 indicates that it is not very likely, only a 5 percent chance, that the Super Bowl would induce an impact of a magnitude indicated most often by boosters. The likelihood that the impact would be positive is 77 percent, but there is a far greater chance that the impact would be less than zero, than in the $\$ 300$ to $\$ 400$ million dollar range.

Other ex post studies also arrive at the conclusion that the NFL's mega-events generate economic benefits that are a fraction of those claimed by the league. Baade and Matheson (2000), Baade, Baumann, and Matheson (2008), and Coates (2006) all examine the impact of the Super Bowl on tax collections in the host city. The NFL has previously reported that the Super Bowl was responsible for a $\$ 670$ million increase in taxable sales in the Miami region in 1999. By contrast, Baade and Matheson (2000) found that after accounting for the impact of inflation, population growth, and normal real income growth, South Florida experienced a bump of at most, a $\$ 36.9$ million from Super Bowl XXXIII. Similarly, Coates (2006) and Baade, Baumann, and Matheson (2008) found only small retail sales or sales taxes increases from the Super Bowl.

Baumann, Matheson, and Muroi (2009) examined the economic impact of the Pro Bowl on the Hawaiian economy and while they concluded that the game generated a 
positive and significant effect (meaningfully different from zero in the jargon of statisticians), the amount of Hawaii Tourism Authority resources devoted to the NFL event reflected on the monopoly power of the NFL rather than on the impact of the Pro Bowl relative to other sports events such as the Hawaii Marathon or the Ironman Triathlon. All three events attracted a roughly comparable number of additional visitors to Hawaii, but significantly more public money was spent on the Pro Bowl than on either the Marathon or Triathlon. Furthermore, the authors clearly identify that Pro Bowl visitors crowd out other tourists. While 27,000 out-of-state visitors typically attended the Pro Bowl when it was held in Hawaii, the state only experienced an average increase in tourist arrivals of just under 7,000 visitors. In other words, on average 20,000 regular tourists were displaced by sports fans during the week of the Pro Bowl.

\section{Conclusions and Policy Implications}

The Super Bowl is unquestionably the most important annual sporting event held in the United States commanding the nation's attention like no other game. Civic leaders, aided by rosy economic impact statements published by the league or other sports boosters, are led to believe that the national spotlight brings with it significant monetary rewards for the host city. Economists, however, have long been skeptical of boosters' claims regarding the economic impact of mega-events such as the Super Bowl or lesser events like the Pro Bowl. While these games may be large in a gross sense, their net impact is limited by the substitution effect, crowding out, and leakages. Ex post analyses of the Super Bowl, as well as the NFL's other premier event, the Pro Bowl, suggest that the true economic impact of these games is a fraction of what is claimed. If the price tag 
for the right to host such an event is the construction of a new stadium with a significant public contribution of funds, then cities would be wise to view any league claims of economic largesse from the Super Bowl or Pro Bowl with suspicion. Ex ante dreams often lead to a disappointing ex post reality.

\section{Note:}

This paper updates and extends our previous work on this topic. Portions of this chapter draw heavily from Baade and Matheson (2006), "Padding Required: Assessing the Economic Impact of the Super Bowl," European Sport Management Quarterly, Vol. 6, No. 4. 


\section{$\underline{\text { References }}$}

Arthur Andersen, Hospitality and Leisure Services. "The Sydney Olympic Performance Survey: The Sydney Olympic Games on the Australian Hotel Industry.” Mimeograph, 2000, 1-7.

Baade, R. "Professional Sports as a Catalyst for Metropolitan Economic Development." Journal of Urban Affairs, 18(1), 1996, 1-17.

Baade, Robert, Robert Baumann and Victor Matheson (2008). Selling the Game: Estimating the Economic Impact of Professional Sports through Taxable Sales. Southern Economic Journal, 74: 794-810.

Baade, Robert and Victor Matheson (2000). An Assessment of the Economic Impact of the American Football Championship, the Super Bowl, on Host Communities. Reflets et Perspectives, 30: 35-46.

Baade, Robert and Victor Matheson (2006). Padding Required: Assessing the Economic Impact of the Super Bowl. European Sports Management Quarterly, 6: 353-374.

Baumann, Robert, Victor Matheson, and Chihiro Muroi, Bowling in Hawaii: Examining the Effectiveness of Sports-Based Tourism Strategies, Journal of Sports Economics, Vol. 10:1, 107-123.

Coates, Dennis (2006). The tax benefits of hosting the Super Bowl and the MLB All-Star Game: the Houston experience. International Journal of Sport Finance, 1.

Coates, Dennis and Brad Humphreys (2002). The Economic Impact of Post-Season Play in Professional Sports. Journal of Sports Economics, 3: 291-299.

Davidson, L. "Choice of a Proper Methodology to Measure Quantitative and Qualitative Effects of the Impact of Sport." in The Economic Impact of Sports Events, ed. 
Claude Jeanrenaud. Neuchatel, Switzerland: Centre International d'Etude du Sport, 1999, 9-28.

Feddersen, Arne, André Leão Grötzinger, and Wolfgang Maennig, (2009). "Investment in Stadia and Regional Economic Development_Evidence from FIFA World Cup 2006," International Journal of Sport Finance, 4:4, 221-239.

Humphreys, Jeffery (1994). The Economic Impact of Hosting Super Bowl XXVIII on Georgia. Georgia Business and Economic Conditions, May-June, 18-21.

Mills, E. and McDonald, J. eds. Sources of Metropolitan Growth, New Brunswick, N.J.: Center for Urban Policy Research, 1992.

National Football League (1999). Super Bowl XXXII generates \$396 million for South Florida. NFL Report, 58.

Peter, J. "Building NFL Fortunes." The Times-Picayune, Section C, p. 1, July 14, 2002.

Porter, Philip (1999). Mega-Sports Events as Municipal Investments: A Critique of Impactc Analysis. In Fizel, J., Gustafson, E. \& Hadley, L. Sports Economics: Current Research.Westport, CT: Praeger Press.

Seigfried, J. and Zimbalist, A. "A Note on the Local Economic Impact of Sports Expenditures." Journal of Sports Economics, 3:4, 2002, 361-366.

Steeg, Jim (1999). Inquiring Minds Should Know. Fox Sports Biz online; posted November 9, 1999. 